\title{
A NOVA GESTÃo PÚBLICA NA EDUCAÇÃO: uma análise das escolas "concertadas" na Espanha
}

\section{JULIANO MOTA PARENTE}

Universidade Estadual Paulista. Pós-doutor em Educação pela Universidade de Salamanca, Espanha. Doutor em Educação (UNESP/Presidente Prudente). Mestre em Educação (UNISAL). Membro do Grupo de Pesquisa e Avaliação de Políticas Educacionais (GAPE/UNESP/Marília). ORCID: 0000-0001-6309-9632. E-mail: julianomparente@gmail.com 


\title{
A NOVA GESTÃo PÚBLICA NA EDUCAÇÃO: uma análise das escolas "concertadas" na Espanha
}

O objetivo deste artigo é analisar a Nova Gestão Pública (NGP) na educação, investigando que elementos influenciaram o sistema educacional na Espanha. A administração pública moderna tem utilizado nas últimas décadas estratégias cada vez mais racionalistas, alinhadas a uma tendência de organização dos processos de gestão no contexto da globalização e da mercantilização dos serviços públicos. Neste sentido, os sistemas educacionais reproduzem esse contexto histórico, incorporando em suas práticas ações que reverberam as políticas de governo, corroborando as tendências internacionais que se amplificam no âmbito da globalização. O presente trabalho configura-se como um ensaio teórico que se fundamenta na legislação educacional por meio de elementos formais que nos auxiliaram na elaboração das categorias de análise. Diante das evidências apresentadas, podemos concluir que a NGP como um fenômeno internacional, tem sido incorporada na administração pública de vários países, inclusive na Espanha, com a argumentação de modernização do Estado e efetivação de mecanismos de monitoramento e regulação, influenciando nos sistemas educacionais de forma a estabelecer uma educação padronizada com foco no resultado.

Palavras-chave: Educação. Nova Gestão Pública. Sistemas Educacionais.

\section{THE NEW PUBLIC MANAGEMENT IN EDUCATION: an analysis of "concerted" schools in Spain}

The purpose of this article is to analyze the New Public Management (NPM) in education, investigating which elements influenced the educational system in Spain. Modern public administration has used increasingly rationalist strategies in recent decades, aligned with a tendency to organize management processes in the context of globalization and commodification of public services. In this sense, educational systems reproduce this historical context, incorporating in their practices actions that reverberate with government policies, corroborating international trends that are amplified in the scope of globalization. The present work is configured as a theoretical essay that is based on educational legislation through formal elements that helped us in the elaboration of the analysis categories. In view of the evidence presented, we can conclude that NPM as an international phenomenon, has been incorporated into the public administration of several countries today, including in Spain, with the argument of modernization of the State and the implementation of monitoring and regulation mechanisms, influencing educational systems so as to establish a standardized education focused on results.

Keywords: Education. New Public Management. Educational Systems.

\author{
plurais \\ Salvador, v.5, n.1 p.241-260, jan/abr. 2020
}




\section{LA NUEVA GESTIÓN PÚBLICA EN EDUCACIÓN: un análisis de las escuelas "concertadas" en España}

El propósito de este artículo es analizar la Nueva Gestión Pública (NGP) en educación, investigando qué elementos influyeron en el sistema educativo en España. La administración pública moderna ha utilizado estrategias cada vez más racionalistas en las últimas décadas, alineadas con una tendencia a organizar los procesos de gestión en el contexto de la globalización y comercialización de los servicios públicos. En este sentido, los sistemas educativos reproducen este contexto histórico, incorporando en sus prácticas acciones que repercuten en las políticas gubernamentales, corroborando las tendencias internacionales que se amplifican en el ámbito de la globalización. El presente trabajo se configura como un ensayo teórico que se basa en la legislación educativa a través de elementos formales que nos ayudaron en la elaboración de las categorías de análisis. En vista de las evidencias presentadas, podemos concluir que NGP como fenómeno internacional, se ha incorporado a la administración pública de varios países, incluida España, con el argumento de modernizar el Estado e implementar mecanismos de monitoreo y regulación, que influyen en los sistemas educativos en Brasil. para establecer una educación estandarizada centrada en los resultados.

Palabras clave: Educación. Nueva administración pública. Sistemas Educativos. 


\section{A NOVA GESTÃo PÚBLICA NA EDUCAÇÃO: uma análise das escolas "concertadas" na Espanha}

\section{Introdução}

A administração pública moderna tem utilizado nas últimas décadas estratégias cada vez mais racionalistas, alinhadas a uma tendência de organização dos processos de gestão no contexto da globalização e da mercantilização dos serviços públicos. Dos autores que estudam a temática, Subirats et al. (2008) destaca que as diretrizes neste cenário estão carregadas de elementos tecnocráticos, que nem sempre refletem as demandas da sociedade, desarticulando-se das políticas sociais e educacionais.

Diante deste panorama, percebemos que a gestão educacional, bem como as políticas públicas por ela desencadeadas, se convertem em instrumentos de legitimação das lógicas de mercado neoliberais, fomentando um Estado regulador dos serviços públicos que estabelece um “acordo político do Pós-Estado da providência” (BALL, 2004, p. 1.106).

Neste sentido, os sistemas educacionais reproduzem esse contex to histórico, incorporando em suas práticas ações que reverberam as políticas de governo, corroborando as tendências internacionais que se amplificam no âmbito da globalização. Na atualidade, autores que estudam a temática (VERGER; NORMAN, 2015; HALL; GUNTER, 2015; VELEZ; ORTIZ, 2016) advertem que a educação pública vem sendo desenvolvida em diversas partes do mundo sob a influência de modelos ligados à Nova Gestão Pública (NGP) e a Pós-Nova Gestão Pública (PNGP). Tendo em vista que a PNGP é reconhecida como um referencial teórico mais recente, levando em conta que muitos países ainda nem sentiram os seus efeitos, vamos considerar neste artigo a Nova Gestão Pública como o contexto atual em que se consolidou o sistema educacional espanhol.

O objetivo deste artigo é analisar a Nova Gestão Pública na educação, investigando que elementos influenciaram o sistema educacional na Espanha. Nossa questão de pesquisa é quais os fatores que influenciaram o sistema educacional espanhol no âmbito da Nova Gestão Pública?

\footnotetext{
plurais 
Para atingir este objetivo discutiremos a partir de dois fundamentos da NGP, que se configuram como nossas categorias de análise: a descentralização e as parcerias público-privadas. Dessa forma, poderemos verificar se o processo de descentralização e as parcerias público-privadas no contexto da educação na Espanha estão alinhadas ao modelo da Nova Gestão Pública.

O presente trabalho configura-se como um ensaio teórico baseado em pesquisa documental, que investigou possíveis confluências entre o arranjo do sistema educacional espanhol e os fundamentos da teoria Nova Gestão Pública (NGP), e, sua possível caracterização como um fenômeno global inserido no âmbito da comunidade européia. Ao mesmo tempo nos fundamentamos na teoria econômica internacional (COHEN, 2008), que aborda possíveis confluências entre sistema políticos, relacionados a aspectos sociais, culturais e geográficos, concernentes a transferências políticas realizadas pelos governos (STEINER-KHAMSI, 2015).

Em termos estruturais o trabalho foi dividido em três subitens: no primeiro faremos um breve diagnóstico do sistema educacional espanhol, apresentando algumas características que auxiliarão nas reflexões suscitadas posteriormente. No segundo item, faremos uma abordagem sobre o processo de descentralização da educação na Espanha e por fim, no último item, analisaremos alguns aspectos das escolas concertadas, uma das estratégias das parcerias público-privadas estabelecidas no âmbito da gestão educacional espanhola.

\section{Características do sistema educacional espanhol}

A Espanha é um país da Europa situado na península ibérica com uma população de quase 47 milhões de pessoas (ESPANHA, 2020). O país que faz parte da União Europeia é uma monarquia parlamentarista dividida em 17 Comunidades Autônomas e 2 cidades autônomas, que congregam 50 províncias e 8.131 municípios.

No que se refere ao sistema educacional, que na Espanha, historicamente, sempre foi fortemente centralizado, experimenta nas últimas décadas uma descentralização intermediária, fundamentada na divisão de poder entre o governo central e as Comunidades Autônomas (PUELLES, 1993). Com base na Ley Orgánica de Ordenación General del Sistema Educativo (LOGSE), que estabelece as diretrizes e a estrutura do sistema educacional espanhol, as Comunidades Autônomas são responsáveis pela organização e oferta de todos os níveis de educação (ESPANHA, 1990). 
Considerada uma das leis mais importantes da educação na Espanha, a LOGSE propõe uma série de mudanças que estimulam a autonomia dos centros escolares e ampliação da qualidade educativa.

Legitimando as reformas educacionais propostas no final do século XX, a LOGSE materializa uma conjuntura de racionalidade educacional alinhada aos marcos regulatórios e programas implementados por vários países da União Europeia, fortalecendo um modelo de gestão denominado Nova Gestão Pública (NGP).

De acordo com os dados do Ministério da Educação a Espanha tem hoje no regime geral de ensino (educação básica) um total de 8.217.651 alunos matriculados. Deste total, 67\% fazem parte da rede pública de ensino e 33\% estão matriculados em instituições privadas (ESPANHA, 2020). O Auadro 1 mostra como estão organizados os níveis da Educação Básica no sistema educacional espanhol.

Figura 1: Níveis da Educação Básica na Espanha

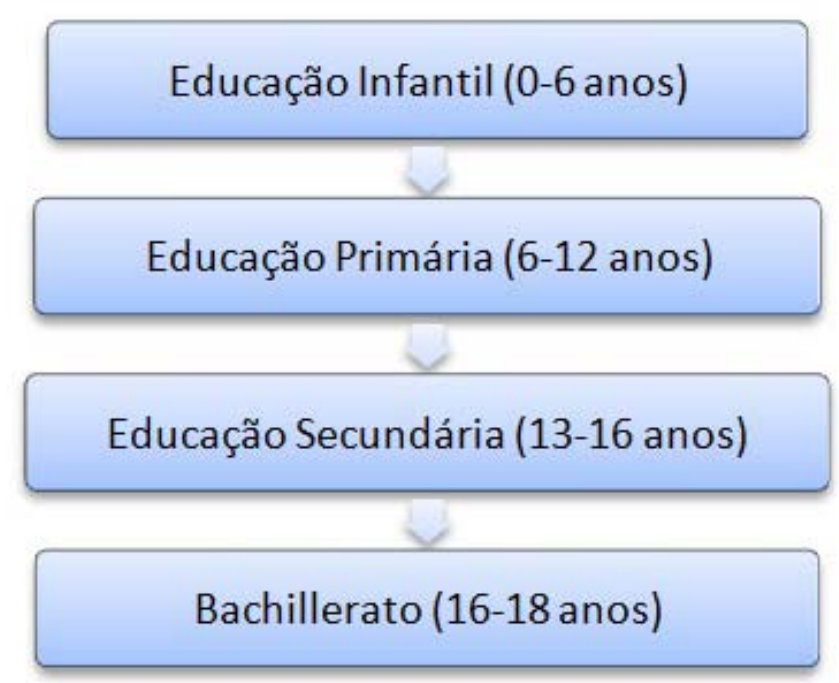

Fonte: Elaborado pelo Autor. 
Conforme mostrado no Quadro 1, a educação básica na Espanha é composta por quatro níveis: educação infantil, educação primária, educação secundária (ESO) e bachillerato. A educação infantil, equivalente a do Brasil, abrange um período de seis anos, compreende as idades de 0 a 6 anos. A educação primária, dos seis aos doze anos e a educação secundária dos 13 aos 16 anos. A educação primária e secundária equivalem ao Ensino Fundamental brasileiro, sendo que na Espanha o aluno leva dez anos para concluir e no Brasil nove anos. O bachillerato tem uma duração de dois anos e equivale ao Ensino Médio no Brasil que tem uma duração de três anos. De acordo com a legislação espanhola (ESPANHA, 1990), a educação infantil e o bachillerato não são obrigatórios, ficando a obrigatoriedade para educação primária e secundária.

O sistema educacional espanhol, assim como vários países da Europa, vem desenvolvendo políticas públicas que fortalecem o discurso da melhoria da qualidade da educação, desencadeando processos educacionais no contexto da consolidação da NGP. Na Espanha, a NGP «tem estimulado o maior alcance político da avaliação educativa e a maior presença de planos estratégicos e indicadores de desempenho» (VERGER; NORMAN, 2015, p. 603, tradução nossa).

Esse panorama vem se propagando em vários países da Europa alinhado com a tendência de construção de um modelo padrão de educação que se materializa por meio de uma «agenda global estruturada para a educação» (DALE, 2004). Este posicionamento do bloco europeu fortalece a argumentação da construção de sistemas educacionais padronizados, utilizando largamente o monitoramento do rendimento dos alunos, enfatizando o ranqueamento educacional medido através de avaliações em larga escala padronizadas (Pisa) ${ }^{1}$.

Neste sentido, a Espanha intensifica um processo de avaliação das escolas e dos alunos, elaborando índices estatísticos que se propõem a medir a qualidade da educação oferecida no país. Tianna-Ferrer (2018) analisando o sistema educacional espanhol nos últimos trinta anos destaca que a partir da década de 1980, o país começa a avaliar os centros educacionais com ênfase no currículo e no desempenho dos alunos. Segundo o autor, as políticas de avaliação educacional desenvolvidas nas últimas décadas na Espanha tem se mostrado incoerente entre as intenções apresentadas e as ações práticas efetivamente implementadas.

1 Programme for International Student Assessment.

\section{plurais}


Puelles (2016) acrescenta que houve uma excessiva proliferação de leis educacionais que trouxeram uma instabilidade legislativa, comprometendo o fortalecimento do sistema educacional espanhol. Corroborando com as diretrizes da NGP, destacamos a Ley Orgánica Reguladora del Derecho a la Educación (ESPANHA, 1985) que regulariza os centros "concertados", repassando recursos para instituições privadas na oferta da educação, a Ley Orgánica de la Participación, la Evaluación y el Gobierno de los Centros Docentes (ESPANHA, 1995) com foco no rendimento escolar e qualidade da educação e a Ley Orgánica de la Mejora de la Calidad Educativa (ESPANHA, 2013) centrada na padronização dos processos formativos com vistas a atingir os níveis educacionais estabelecidos pelos organismos internacionais.

Diante das reflexões apresentadas, podemos inferir que a forte interferência da NGP vem direcionando as políticas públicas educacionais na Espanha para a padronização dos sistemas em contextos diferenciados. Não há dúvida que estes aspectos impactam na autonomia das escolas e de toda a equipe escolar. Na Espanha, a autonomia é caracterizada pelo excesso de normativismo, no âmbito da tradição gerencialista, "incrustada na cultura organizativa da administração" num contexto em que "a autonomia escolar se coloca em segundo plano" (BOLÍVAR, 2009, p. 52).

De acordo com o autor, a autonomia na gestão da educação tem sido utilizada como um "regime de regulação pós-burocrática" muito frequente nos países da Europa, em condições de "quase mercado", que podem comprometer a dinâmica de funcionamento e a identidade institucional das escolas.

\section{Modelos de gestão da educação baseados na descentralização}

As Reformas na administração pública implementadas no final do século XX impactaram na gestão educacional em diversos países da Europa. Influenciadas pela corrente gerencialista iniciada nos Estados Unidos e na Grã Bretanha, que depois se espalhou para diversas partes do mundo (PARENTE, 2018), as Reformas consolidaram a Nova Gestão Pública (NGP) num cenário de reformulação dos sistemas educacionais.

Para Van Gestel e Teelken (2004, p. 437) a NGP se apresenta como um novo paradigma da administração pública que "mantém as ideias da administração central que consideram como aspectos chave a direção, a administração e o controle" (tradução nossa).

\section{plurais}


Culebro Moreno (2014) destaca que a NGP é um fenômeno multidimensional que incorporou na administração pública uma grande variedade de princípios e ferramentas de gestão. Parcerisa (2016, p. 362) afirma que a NGP começou a impactar na educação espanhola por meio de ações governamentais realizadas nas escolas da Catalunha e na Andalucía. "No âmbito educativo, a NGP é traduzida na incorporação de sistemas de avaliação padronizados, na publicação de resultados estatísticos que fomentam a competição entre as escolas e na autonomía institucional das unidades escolares" (tradução nossa).

Um dos pilares centrais da NGP foi a criação de mecanismos de descentralização da educação, atribuindo aos governos locais a responsabilidade da oferta da educação pública. Ainda que a descentralização seja vista como uma conquista de governos democráticos, paradoxalmente ela é utilizada como uma ferramenta estratégica gerencial no fortalecimento da NGP: descentraliza-se a execução enquanto a gestão continua centralizada.

Viñao (2000, p. 2), ao analisar o impacto das Reformas no sistema educacional da Espanha esclarece que ao desconsiderar o processo histórico de construção das práticas relacionadas ao processo de aprendizagem a Reforma não atingiu seu objetivo, pois ignorou "a existência e o peso do conjunto de tradições e regularidades institucionais sedimentadas ao longo do tempo" (tradução nossa).

Puelles (1993) faz uma profunda reflexão acerca do tema, classificando os modelos de gestão educacional por meio do nível de descentralização utilizado por cada país. O autor nos esclarece que é um tema muito complexo e não se pode analisar de forma superficial, levando em conta somente suas "vantagens e inconvenientes", mas sim considerar que "se trata de uma opção pela qual pesam fatores históricos e fatores políticos que condicionam fortemente a opção escolhida" (PUELLES, 1993, p. 15, tradução nossa).

Portanto para nossa análise, seguindo o referencial do autor, podemos considerar que os critérios que influenciam a adoção de modelos de gestão educacional são: a organização política territorial (sistema político), os fatos históricos e o contexto de desenvolvimento atual. O Quadro 2 mostra a relação entre os modelos de gestão educacional dos países e seus respectivos sistemas políticos. 
Quadro 2: Modelos de gestão educacional dos países

\begin{tabular}{|l|l|l|}
\hline \multicolumn{1}{|c|}{ Modelo de Gestão } & \multicolumn{1}{|c|}{ Países } & \multicolumn{1}{c|}{ Sistema Político } \\
\hline Centralizado & $\begin{array}{l}\text { França, Irlanda, Grécia, Bolívia, Equa- } \\
\text { dor, Paraguai, Portugal, Costa Rica, } \\
\text { Panamá e Peru. }\end{array}$ & Unitário \\
\hline Descentralização intermediária & Itália e Espanha & Unitário \\
\hline Descentralização federal & $\begin{array}{l}\text { Austrália, Alemanha, Argentina, Brasil, } \\
\text { México, Venezuela. }\end{array}$ & Federalismo \\
\hline $\begin{array}{l}\text { Descentralização federal e muni- } \\
\text { cipal }\end{array}$ & Suíça, Estados Unidos & Federalismo \\
\hline $\begin{array}{l}\text { Descentralização municipal e aca- } \\
\text { dêmica }\end{array}$ & Reino Unido & Unitário \\
\hline
\end{tabular}

Fonte: Elaborado pelo autor de acordo com Puelles (1993).

Como podemos verificar, a tendência é que os países que têm um sistema político unitário sejam mais centralizados. Segundo Puelles (1993), a gestão educacional centralizada predomina em quase todos os países do mundo na atualidade, sendo subdivididas em dois grupos: centralizado absoluto (países da África e Ásia), e os países com tendências de centralização (Portugal, França e Costa Rica).

O segundo critério refere-se aos fatos históricos e seus reflexos nas políticas educacionais. "As considerações históricas explicam porque a maioria dos países, na atualidade, vive em regimes de centralização" (PUELLES, 1993, p. 15, tradução nossa). De acordo com o autor, as experiências vividas e como foi sendo estruturado o sistema educacional, pautam políticas públicas vinculadas a essas concepções.

Finalmente o terceiro critério destaca o contexto atual, baseado na participação da sociedade, nas lutas dos movimentos sociais e no envolvimento das famílias no processo de formação de seus filhos. Destaca-se aqui também o nível de engajamento da comunidade local na gestão da escola em ações relacionadas à Associação de Pais e Mestres, eleição de diretores, etc.

Entretanto há que se destacar o caráter dinâmico da administração pública, no que se refere à dimensão territorial. Neste sentido, a descentralização poderá ser maior ou menor de acordo também com o contexto político e econômico do país. "A distribuição territorial do poder não é uma

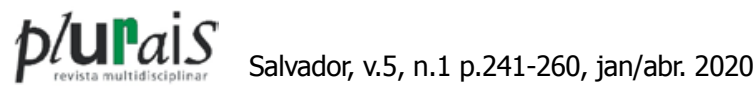


coisa fixa, algo que os países decidem de uma vez por todas em sua ata de nascimento político; não é algo estático e sim algo fundamentalmente dinâmico" (PUELLES, 1993, p. 16, tradução nossa).

Conforme destacado pelo Quadro 2, a Espanha possui um nível de descentralização intermediária, pois transfere às Comunidades Autônomas a atribuição de organização e oferta da educação em cada região. De acordo com Blanch (2011), a descentralização do sistema educacional espanhol se inicia em 1978 com a promulgação da Constituição que estabelece as primeiras diretrizes de transferência do governo central para as Comunidades Autônomas. O processo de inicia efetivamente em 1981 com os Estatutos de Autonomia, que amparados pela Carta Magna, delimitam atribuições e competências.

El Estado se reserva las normas básicas sobre la ordenación general del sistema educativo, la regulación de las condiciones para la obtención de los títulos académicos y la fijación de los aspectos básicos del currículo; en cambio, las comunidades autónomas tienen competencia plena sobre los centros docentes, profesores y alumnos; expiden los títulos académicos, supervisan o inspeccionan el sistema educativo y gozan de autonomía financiera (BLANCH, 2011, p. 12).

O formato de descentralização espanhol se assemelha muito com o utilizado por outros países: o governo central fica responsável pelas políticas gerais e as Comunidades Autônomas organizam as questões acadêmicas (currículo, professores, gestão da escola). Possivelmente o aspecto divergente é a autonomia financeira.

Puelles (1993) apresenta as principais características de um modelo de descentralização intermediária, que de acordo com o seu estudo foi atribuído à Espanha.

Quadro 3: Principais características dos modelos de descentralização intermediária

\begin{tabular}{|l|l|l|}
\hline \multicolumn{1}{|c|}{ Modelo } & \multicolumn{1}{|c|}{ Característica } & \multicolumn{1}{c|}{ País } \\
\hline $\begin{array}{l}\text { Modelo de descentralização } \\
\text { intermediária }\end{array}$ & - Intermediário entre o centralizado e o federal; & Espanha \\
& $\begin{array}{l}\text { - Longa tradição de centralidade porém começam a } \\
\text { atribuir competências aos territórios, províncias, dis- } \\
\text { tritos ou municípios; }\end{array}$ & $\begin{array}{l}\text { - A Constituição autoriza a criação de uma instituição } \\
\text { territorial intermediária entre o poder central e as co- } \\
\text { munidades locais. }\end{array}$ \\
\hline
\end{tabular}

Fonte: Elaborado pelo autor de acordo com Puelles (1993). 
O Quadro 3 destaca três aspectos da descentralização intermediária: é um modelo que se localiza entre o centralizado e o federal, característico de países com longa tradição centralizadora que se abrem politicamente e a legislação cria uma instituição intermediária entre o governo central e a comunidade local.

Puelles destaca ainda que o ponto central na descentralização da educação na Espanha é que ela foi total na dimensão administrativa e quase total na dimensão política. Segundo o autor, a descentralização política é muito significativa porque as Comunidades Autônomas "tem amplo poder legislativo, o que somados a autonomia financeira, permite as comunidades a adoção de políticas educativas diferentes, distintas inclusive das do governo central" (PUELLES, 1993, p. 27, tradução nossa).

Neste sentido, cabe ainda destacar que a efetividade de um processo de gestão não depende somente do caráter legal, mas, sobretudo, das condições que são estabelecidas para que ela ocorra. "A simples delegação da gestão, se as decisões continuam sendo tomadas pela Administração central, não é descentralização; a esse outro processo se chama desconcentração" (GARCIA, 2015, p. 204, tradução nossa).

Diante de tantas variáveis é possível afirmar que o processo de descentralização educacional de um país é uma tarefa muito complexa. No caso específico da Espanha, objeto de estudo deste artigo, percebe-se traços históricos muito marcantes, diante de um país que viveu a ditadura franquista ao longo de quase 40 anos e que sentiu a necessidade de fortalecimento dos governos locais e da participação da sociedade em geral.

\section{As escolas "concertadas" na Espanha como estratégia de parcerias público- privadas}

A estrutura organizacional do sistema educacional espanhol compreende dois tipos de escolas, de acordo com a titularidade jurídica: centros escolares públicos e centros escolares privados. Os centros escolares públicos são escolas mantidas e reguladas pelo Estado. Os centros escolares privados se subdividem em escolas privadas, cuja titularidade seja uma pessoa física ou jurídica de caráter privado e os centros "concertados", que são juridicamente instituições privadas, mas que recebem recursos públicos para a manutenção de suas atividades.

\section{Plullais Salvador, v.5, n.1 p.241-260, jan/abr. 2020}


Tanto as escolas públicas como as privadas fazem parte do sistema educacional na Espanha, tendo que respeitar a legislação específica que regulamenta o seu funcionamento. O que diferencia os centros escolares privados dos "concertados" é basicamente a transferência de recursos financeiros para as escolas concertadas, que não ocorre no caso das escolas privadas. Entretanto, ambas (privada e "concertada") tem autonomia na gestão escolar, desde que cumpram os requisitos estabelecidos por lei.

As denominadas escolas “concertadas", que já existiam na Espanha há muito tempo, passaram a receber essa denominação no contexto das reformas educacionais na década de 1980, por meio da Ley Orgánica 8, de 3 de julho de 1985, que regula o direito à Educação. De acordo com o preâmbulo da referida lei, em consonância com a Ley 14/1970 que determina a obrigatoriedade e gratuidade do ensino básico, a opção por agregar as escolas "concertadas" ao sistema educacional de forma mais efetiva ocorre em função do aumento da demanda de escolarização básica na Espanha a partir da década de 1980 e a falta de recursos por parte da administração pública para ampliar a oferta de vagas.

De acordo com a Ley 8/1985, se enquadram no regime de centros privados "concertados" as instituições que "en orden a la prestación del servicio público de la educación en los términos previstos en esta Ley, impartan la educación básica y reúnan los requisitos previstos en este Título" (ESPANHA, 1985). A lei cria um "novo modelo" de escola, situado entre o público e o privado, que atendendo a uma necessidade emergencial, se incorpora ao sistema educacional espanhol com autonomia de gestão, porém agora regulada pelo Estado.

Analisando as escolas "concertados" sob a ótica da Nova Gestão Pública, verificamos a utilização de uma das estratégias mais recorrentes das políticas neoliberais do final do século XX: as parcerias público-privadas. Para Verger, Curran e Parcerisa (2015, p. 680) "esta alianza público-privada que rige el sistema educativo español desde mediados de los ochenta permitió, en sus comienzos, lograr una rápida expansión educativa a bajo coste".

O que deveria ser uma medida emergencial que objetivava minimizar os efeitos de uma crise econômica que agravou a situação educacional na Espanha na década de 1980, acabou se tornando uma regra incorporada ao sistema educacional. Atualmente, se considerarmos a quanti- 
dade de alunos da educação básica na Espanha, 33\% estão matriculados em instituições privadas, sendo que $78 \%$ deste percentual são de instituições concertadas.

O surgimento das escolas "concertadas" ocorre num momento histórico de consolidação do processo democrático na Espanha, impulsionado pela necessidade de criar estratégias que possibilitassem o desenvolvimento social e educacional em consonância com o crescimento econômico, de forma a garantir a universalidade da educação, principal desafio da área educacional no final do século XX.

Entretanto, alguns autores questionam esta nova configuração do sistema educacional espanhol. Agudo e Lacruz (2012, p. 88) entendem que as subvenções destinadas às escolas "concertadas" são uma forma "de privatización explícita y visible, donde el dinero público sirve para financiar un centro totalmente privado, que dispone de unas reglas de juego similares en teoría [...] pero en la práctica son totalmente diferentes".

Os autores se referem à autonomia na gestão escolar, tendo em vista que as escolas "concertadas" não dependem de autorização direta do Poder Público no que se refere ao planejamento e execução de suas atividades (currículo, contratação de professores, atividades extra-escolares, etc.). Na prática, a única medida que vincula as concertadas ao sistema público é a obrigatoriedade de informar a quantidade de vagas disponíveis para que a administração local (Direcciones Provinciales das Comunidades Autônomas) faça a distribuição dos alunos de acordo com a demanda e os critérios estabelecidos em lei.

Para LLera e Perez (2012, p. 98), as escolas "concertadas" na Espanha são uma "mistura jurídica" entre sua titularidade privada e subvenção pública que se justificou na década de 1980 em função do crescimento demográfico e da ampliação da escolarização obrigatória, mas que hoje é questionada. De acordo com os autores, "el crecimiento del número de unidades escolares en centros concertados ya no se justifican por la insuficiencia de los centros públicos para atender la demanda, sino por otro tipo de razones».

Além da peculiaridade que permeia o enquadramento das escolas "concertadas" na Espanha, outras questões vêm sendo apontadas no sentido de questionar a necessidade de incorporar os centros escolares "concertados" ao sistema educacional espanhol. Em seu artigo intitulado «

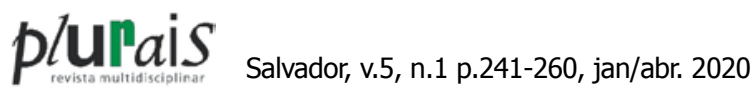


Colegios concertados y selección de escuela en España: un círculo vicioso", Llera e Pérez (2012) discutem os motivos que levam as famílias a preferir matricular seus filhos em escolas concertadas.

De acordo com os autores, a crescente presença da iniciativa privada no sistema educacional espanhol tem estimulado a competitividade entre escolas, que são disputadas pelas famílias num «mercado educacional» que se baseia na eficiência e na qualidade dos serviços, característica marcante da NGP.

Diante desse panorama, os autores constataram que a presença das escolas "concertadas" no sistema educacional espanhol vem gerando uma segregação econômica visível na sociedade atual. «Las plazas en los colegios privados serán copadas por alumnado de extracción socioeconómica media-alta y la red pública se verá compuesta mayoritariamente por estudiantes de colectivos desfavorecidos o inmigrantes» (LLERA e PÉREZ, 2012, p. 107).

A Tabela 1 apresenta os dados referentes a quantidade de escolas nos últimos dez anos na Espanha.

Tabela 1: Evolução da quantidade de escolas na Espanha por titularidade.

\begin{tabular}{|l|l|l|l|l|}
\hline \multicolumn{1}{|c|}{ Número de escolas } & \multicolumn{1}{|c|}{$\mathbf{2 0 0 7 - 2 0 0 8}$} & \multicolumn{1}{c|}{$\mathbf{1}$} & \multicolumn{1}{c|}{$\mathbf{2 0 1 7 - 2 0 1 8}$} & \multicolumn{1}{c|}{$\%$} \\
\hline Públicas & 18.050 & 71 & 19.061 & 67 \\
\hline Concertadas & 4.095 & 16 & 5.285 & 19 \\
\hline Privadas & 3.297 & 13 & 4.034 & 14 \\
\hline Total & 25.442 & 100 & 28.380 & 100 \\
\hline
\end{tabular}

Fonte: Ministério da Educação da Espanha (2020).

De acordo com os dados apresentados na Tabela 1, no ano letivo de 2007-2008, a quantidade de escolas públicas na Espanha representava um percentual de $71 \%$, das escolas "concertadas" $16 \%$ e das escolas privadas $13 \%$. Do total de escolas privadas neste ano letivo, 4.095 eram "concertadas", ou seja, das 7.392 escolas privadas que faziam parte do sistema educacional espanhol $55,4 \%$ era "concertadas", o que representava $16 \%$ 
do total de escolas.

Dez anos depois (2017-2018) o percentual de escolas públicas na Espanha caiu $4 \%$, de $71 \%$ para $67 \%$, enquanto as escolas "concertadas" cresceram 3\%. Mesmo com o aumento de escolas públicas (1.011 escolas), o aumento na quantidade de escolas privadas (1.927) foi muito mais significativo (quase o dobro). Com relação às escolas "concertadas", podemos observar também um aumento na mesma proporção. Nos últimos dez anos houve um aumento na ordem de $77 \%$ na quantidade de escolas "concertadas" na Espanha, o que quer dizer que em dez anos 1.190 escolas foram incorporadas no sistema educacional espanhol com a titularidade "concertada", perfazendo um total de $19 \%$ das instituições na Espanha na atualidade.

O mesmo fenômeno pode ser observado quando analisamos os dados referentes a quantidade de matrículas, conforme destaca a Tabela 2.

Tabela 2: Evolução da quantidade de matrículas de escolas na Espanha por titularidade.

\begin{tabular}{|l|l|l|l|l|}
\hline Quantidade de matrículas & \multicolumn{1}{|c|}{$\mathbf{2 0 0 7 - 2 0 0 8}$} & \multicolumn{1}{c|}{$\mathbf{0}$} & \multicolumn{1}{|c|}{$\mathbf{2 0 1 7 - 2 0 1 8}$} & \multicolumn{1}{c|}{ \% } \\
\hline Públicas & 5.514 .018 & 69 & 5.499 .031 & 67 \\
\hline Concertadas & 1.893 .049 & 24 & 2.090 .770 & 26 \\
\hline Privadas & 534.148 & 7 & 592.595 & 7 \\
\hline Total & 7.941 .215 & 100 & 8.182 .396 & 100 \\
\hline
\end{tabular}

Fonte: Ministério da Educação da Espanha (2020).

Conforme os dados apresentados na Tabela 2, a quantidade de matrículas no ano letivo de 2007-2008 em escolas públicas representavam 69\% dos alunos, ao passo que $31 \%$ estavam matriculados em escolas privadas. De acordo com os dados, $24 \%$ dos alunos estavam matriculados em escolas "concertadas".

Dez anos depois a quantidade de alunos matriculados em escolas públicas baixou para $67 \%$, e, aumentou para $33 \%$, o percentual dos alunos que estudavam em escolas privadas. Com relação aos alunos matriculados em escolas "concertadas", no ano letivo de 2017-2018 houve um aumento de 197.721 alunos, se compararmos ao ano letivo de 2007-2008, representando um

\section{Plullais Salvador, v.5, n.1 p.241-260, jan/abr. 2020}


percentual de $26 \%$ do total de alunos matriculados nas escolas espanholas, ou seja, 1/4 dos alunos na atualidade estudam em escolas "concertadas" na Espanha.

Os resultados obtidos nesse estudo, permitem ratificar a condição de observância do sistema educacional público espanhol com as características da NGP, tendo em vista que a descentralização, materializada por meio da legislação, fomentou a regulação do governo central e a padronização dos sistemas educacionais e a criação das escolas "concertadas" consolidou uma política de relações público-privadas, por meio de repasse de recursos públicos para instituições privadas. Conforme já foi destacado anteriormente, as duas ações estão alinhadas ao modelo da NGP.

\section{Considerações finais}

O presente trabalho objetivou analisar a Nova Gestão Pública (NGP), aqui caracterizada pela adoção de práticas de descentralização e parcerias público-privada, no contexto das políticas educacionais, e sua influência na gestão do sistema educacional da Espanha.

Diante do cenário de adoção de práticas de descentralização, verificadas por meio da organização política e administrativa do governo espanhol, bem como da inserção de arranjos de parcerias público-privadas na perspectiva da inclusão das escolas "concertadas" no âmbito do sistema educacional, podemos concluir que a Espanha aderiu ao modelo de gestão da NGP em escala internacional, considerando sua efetivação em diferentes países da comunidade européia.

Da mesma forma, nossas categorias de análise mostraram uma aproximação das diretrizes da NGP, reproduzindo uma tendência global de estabelecer estratégias comuns para padronizar a educação através dos sistemas educacionais. A descentralização fortalecendo as instâncias locais, reverberando políticas de avaliação em larga escala que subsidiam rankings educacionais e as parcerias público-privadas, como por exemplo, a regulamentação de escolas concertadas para reduzir custos e aumentar a prestação de contas.

Os resultados obtidos no estudo permitem inferir que a concepção dos sistemas públicos educacionais, sob o signo da NGP, têm privilegiado as acepções de racionalidade econômico-administrativa em detrimento dos aspectos culturais e pedagógicos que deveriam demarcar o processo de ensino-aprendizagem. Nesse sentido, recomendamos futuras pesquisas que possam explorar demais características da NGP em diferentes contextos regionais da educação que as delimitações desse estudo não pretendiam explorar ou permitiriam generalizar.

\section{plurais}




\section{REFERENCIAS}

AGUDO, J. L. B.; LACRUZ, J. L. La privatización de la educación pública. Una tendencia en España, un camino encubierto hacia la desigualdad. Revista de Currículum y Formación del Profesorado, v, 16, n. 3, p. 81-109, 2012. Disponível em: https://recyt.fecyt.es/index.php/profesorado/ article/view/42426/24351. Acesso em: 04maio2020.

BALL, S. Performatividade, privatização e o Pós-Estado do Bem-Estar. Educação e Sociedade. Campinas, v. 25, n. 89, p. 1.105-1.126, 2004. Disponível em: https://www.scielo.br/pdf/es/ v25n89/22613.pdf. Acesso em: 01 maio2020.

BOLÍVAR, A. La autonomía en la gestión como nuevo modo de regulación. Espacios en Blanco. Revista de Educación, vol. 19, p. 35-68, jun.2009. Disponível em: https://www.redalyc.org/ pdf/3845/384539801004.pdf. Acesso em: 07maio2020.

BLANCH, J. Descentralización y autonomía en el sistema educativo en España. Italian Journal of Sociology of Education, v. 2, p. 11-30, 2011. Disponível em: http://ijse.padovauniversitypress.it/system/files/papers/2011_2_2.pdf. Acesso em: 07maio2020.

COHEN, B. J. International political economy. An intellectual history. Princeton/Oxford: Princeton University Press, 2008.

CULEBRO MORENO, J. E. Modernización Administrativa y Post-Nueva Gestión Pública: de los dilemas y tensiones hacia las nuevas formas de coordinación y regulación. Revista Mexicana de Análisis Político y Administración Pública. v. 3, n. 1, Disponível em: https://dialnet.unirioja. es/servlet/articulo?codigo $=4722810$. Acesso em: 02maio2020.

DALE, R. Globalização e educação: demonstrando a existência de uma cultura educacional comum ou localizando uma agenda globalmente estruturada para a educação. Educação \& Sociedade, v. 25, n. 87, p. 423-460, mai/ago. 2004. Disponível em: https://www.scielo.br/pdf/es/ v25n87/21464.pdf. Acesso 02maio2020.

ESPANHA, Ley Orgánica 8/1985 de 3 de julio, del Derecho a la Educación. (LODE). Boletín Oficial del Estado, num.159, de 4 de julio, 1985. Disponível em: https://www.boe.es/buscar/act. php?id=BOE-A-1985-12978. Acesso em 02maio2020.

Ley Orgánica 1/1990, de 3 de octubre, de Ordenación General del Sistema Educativo. (LOGSE). Boletín Oficial del Estado de 4 de octubre, 1990. Disponível em: https://www.boe.es/ buscar/doc.php?id=BOE-A-1990-24172. Acesso em: 03maio2020.

Ley Orgánica 8/2013, de 9 de diciembre, para la Mejora de la Calidad Educativa (LOMCE). Boletín Oficial del Estado, num. 295, de 10 de diciembre, 2013. Disponível em: https:// www.boe.es/buscar/pdf/2013/BOE-A-2013-12886-consolidado.pdf. Acesso 03maio2020.

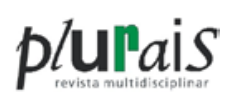


Ley Orgánica 9/1995, de 20 de noviembre, de la Participación, la Evaluación y el Gobierno de los Centros Docentes. (LOPEGSE). Boletín Oficial del Estado, num.278, 1995. Disponível em: https://www.boe.es/buscar/doc.php?id=BOE-A-1995-25202. Acesso em 08maio2020.

Instituto Nacional de Estadística, 2018. Disponível em: https://www.ine.es/dyngs/INEbase/es/operacion.htm?c=Estadistica_C\&cid=1254736176953\&menu=ultiDatos\&i $\underline{\mathrm{dp}}=1254735572981$. Acesso em: 06maio2020.

HALL, D.; GUNTER, H. M. (2015). A Nova Gestão Pública na Inglaterra: a permanente instabilidade da reforma neoliberal. Educação \& Sociedade, 36(132), pp. 743-758. Disponível em: http://www.scielo.br/pdf/es/v36n132/1678-4626-es-36-132-00743.pdf. Acesso em: 01maio2020.

LLERA, R. F.; PEREZ, M. M. Colegios concertados y selección de escuela en España: un círculo vicioso. Presupuesto y gasto público, v. 67, p. 97-118, 2012. Disponível em: https://dialnet. unirioja.es/servlet/articulo? codigo=4014643. Acesso em: 02 maio2020.

PARCERISA, L. Nueva gestión pública y reforma educativa: La recontextualización de la autonomía escolar en diferentes contextos escolares en Cataluña. Revista Portuguesa de Educação, v. 29, n. 2, p. 359-390, 2016. Disponível em: https://revistas.rcaap.pt/rpe/article/view/7928/7480. Acesso 08maio2020.

PARENTE, J. M. Gerencialismo e performatividade na gestão da educação brasileira. Educação em Revista, v. 19, n. 1, p. 89-102, 2018. Disponível em: https://www2.marilia.unesp.br/index. php/educacaoemrevista/article/view/7903. Acesso em: 03maio2020.

PUELLES, M. P. Estudio teórico sobre las experiencias de descentralización educativa. Revista Iberoamericana de Educación, n. 3, p. 13-40, 1993. Disponível em: https://rieoei.org/historico/oeivirt/rie03a01.htm. Acesso em: 05maio2020.

Reflexiones sobre cuarenta años de educación en España o la irresistible seducción de las leyes. Historia y Memoria de la Educación, v. 3, p. 15-44, 2016. Disponível em: http://revistas.uned.es/index.php/HMe/article/view/14760/14118. Acesso em 06maio2020.

RUBIO, J. G. EI proceso de descentralización educativa en España. Edetania: estudios y propuestas socio-educativas, v. 48, p. 203-216, 2015. Disponível em: https://dialnet.unirioja.es/servlet/ articulo?codigo $=5349095$. Acesso em: 4 de maio de 2020 .

SUBIRATS, J. El análisis de las políticas públicas. Gaceta Sanitária, v. 15, n. 3, p. 259-264, 2001. Disponível em: https://www.sciencedirect.com/science/article/pii/S0213911101715579. Acesso em: 03 maio2020.

STEINER-KHAMSI, G. Standards are good (for) business: standardised comparison and the private sector in education, Globalisation, Societies and Education. London: Routledge, 2015. 
Disponível em: https://www.tandfonline.com/doi/abs/10.1080/14767724.2015.1014883. Acesso em: 03maio2020.

TIANA-FERRER, A. Treinta anos de evaluación de centros educativos en Espana. Educación XXI, v. 21, n. 2, p. 17-36, 2018. Disponível em: http://revistas.uned.es/index.php/educacionXX1/ article/view/21419. Acesso em 01 maio2020.

VAN GESTEL, N.; TEELKEN, C. Servicios de educación superior y de seguridad social en los Países Bajos: institucionalismo y nueva gestión política. Gestión y Política Pública. v. 13, n. 2, p. 427-467, 2004. Disponível em: http://www.gestionypoliticapublica.cide.edu/num anteriores/Vol. XIII_No.II_2dosem/Van_Gestel.pdf. Acesso em: 03maio2020.

VÉLEZ, S. A. C.; ORTIZ, C. A. S. Nueva y posnueva gestión pública ¿Continuidad o ruptura de las doctrinas de reforma a partir de 1990? Administración \& Desarrollo, v. 46, n. 1, p. 100125, 2016. Disponível em: https://dialnet.unirioja.es/servlet/articulo?codigo=6403495. Acesso em: 03 maio2020.

VERGER, A.; NORMAND, R., Nueva gestión pública y educación: elementos teóricos y conceptuales para el estudio de un modelo de reforma educativa global. Educação \& Sociedade, v. 36, n. 132, p. 599-622, jul/set. 2015. Disponível em: https://www.scielo.br/pdf/es/v36n132/16784626-es-36-132-00599.pdf. Acesso em: 06 maio2020.

VERGER, A.; CURRAN, M.; PARCERISA, L. La trayectoria de una reforma educativa global: el caso de la nueva gestión pública en el sistema educativo catalán. Educação \& Sociedade, v. 36, n. 132, p. 675-697, jul/set. 2015. Disponível em: https://www.scielo.br/pdf/es/v36n132/16784626-es-36-132-00675.pdf. Acesso em: 07maio2020.

VIÑAO, A. Culturas escolares y reformas: sobre La naturaleza histórica de los sistemas e instituiciones educativas. Revista Teias, Rio de Janeiro, v.1 n. 2, 2000. Disponível em: https://www.e-publicacoes.uerj.br/index.php/revistateias/article/view/23855. Acesso em: 06maio 2020.

Recebido em: 09 de maio de 2020.

Avaliado em: 29 de maio de 2020.

Esta obra está licenciada com uma Licença Creative Commons Atribuição 4.0 Internacional. 